\title{
Itinerari ambiental per la Conca de Tremp
}

\author{
Andreu Serés Aspax \\ IES Terres de Ponent (Mollerussa) \\ aseres@xtec.cat
}

Es presenta un itinerari per la Conca de Tremp estructurat com un conjunt de parades en llocs precisos, amb abundants imatges preses "in situ", explicacions ajustades a cada lloc $i$ qüestions $i$ problemes relacionats amb cada parada. L'article fa referència a una pàgina web dissenyada per subministrar recursos per a que els docents de la matèria Ciències de la Terra i del Medi Ambient (Batxillerat) puguin realitzar una sortida de camp amb els seus alumnes.

\section{Per què més itineraris de natura?}

Aquest és un recurs molt clàssic en el món de les Ciències de la Naturalesa, que ha estat profusament utilitzat per poder veure sobre el terreny alguns dels aspectes tractats en la matèria. Els avantatges que unes poques sortides de camp imprimeixen a la dinàmica de l'aprenentatge són massa obvis per a comentar-los ací.

La tradició que aquest recurs té a Catalunya fa que disposem de nombrosos itineraris principalment enfocats a l'estudi de la Geologia i de la Botànica i, en menor mesura, a d'altres aspectes (històrics, faunístics...). Tot i així, la major part dels itineraris existents estan poc o gens adaptats a l'estudi de les Ciències Ambientals (impactes, riscos, recursos i gestió del territori) i aquest és el buit que pretén omplir, en part, el meu treball.

La idea prové de finals dels 90 , quan l'entrada en vigor de la LOGSE va comportar la substitució de la Geologia de COU per les Ciències de la Terra i del Medi Ambient, de continguts força diferents. Molts professors vam anar readaptant els itineraris de camp als nous continguts, substituint conceptes geològics, desapareguts en la nova matèria, per conceptes relacionats amb les Ciències Ambientals.

Una llicència retribuïda concedida pel Departament d'Educació m'ha permès d'organitzar un material que ja anava utilitzant en dos itineraris: un per la Conca de Tremp i un altre per la Plana de Lleida.

\section{Descripció de la web}

La pàgina web,

http://www.xtec.cat/iesterresdeponent/c naturals/iti nerari conca tremp/index.html

està estructurada en un conjunt de parades ordenades numèricament segons la seva situació. S'accedeix a les parades des d'una taula descriptiva o des d'un mapa sensible (fig. 1).

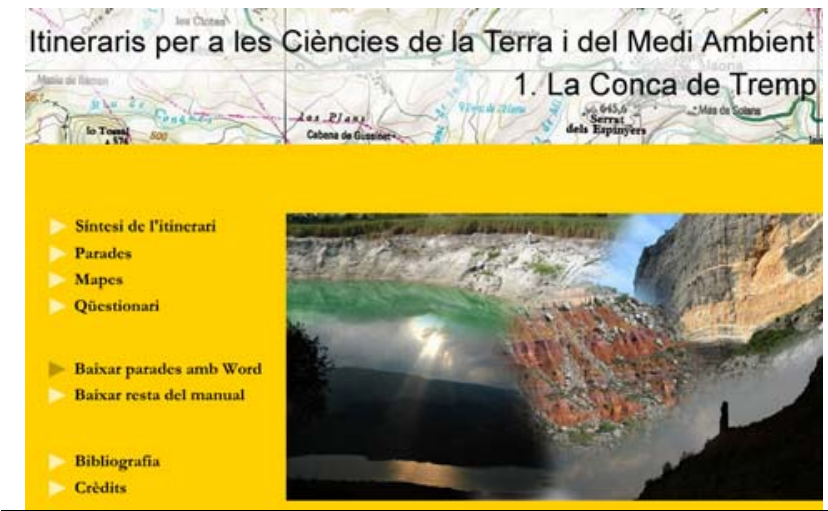

Figura 1. Pantalla de presentació, amb l'índex de la web.

Cada parada conté informació precisa sobre la seva situació (a la xarxa de carreteres i amb coordenades UTM), una breu explicació sobre els conceptes que justifiquen la parada, imatges fotogràfiques de les principals observacions, exposició de l'aspecte ambiental bàsic (risc, impacte, recurs o 
gestió) amb rigor ajustat al nivell de segon de Batxillerat i, sovint, altres observacions secundàries que es poden aprofitar a la mateixa parada.

Entre els enllaços que permeten navegar per la web (índex, parada següent...), n'hi ha que es dirigeixen a problemes i qüestions relacionats amb les observacions i centres d'interès de cada parada.

Encara que el nombre de parades pot ser excessiu per a una jornada, he cregut convenient no dispersar els continguts en itineraris diversos per tal que sigui cada professor qui esculli les parades escaients d'acord als objectius que pretengui.

\section{Itinerari}

L'annex 1 presenta la situació de les 12 parades. La taula que hi apareix esmenta l'objecte d'interès més important de cada lloc, segons el programa de les Ciències de la Terra i del Medi Ambient.

\section{Síntesi dels continguts}

Quan arribeu al coll de Comiols (parada 1), és important que relacioneu el mapa geològic i el tall hidrogeològic amb el territori. És a dir, cal tenir clara la litologia (tipus de roca) i l'estructura (forma i posició relativa dels diferents cossos rocosos) del territori. Únicament la visualització de la realitat geològica tridimensional permetrà als alumnes comprendre el funcionament dels diferents aqüífers lliures i confinats (parada 4-Conques; 5-Basturs, a la figura 3, i 12-Congost de Terradets).

Des del coll de Comiols, es veu perfectament el risc de despreniments que pateix Benavent (parada 2). Malgrat això, fareu la parada més endavant per no carregar massa l'explicació al coll de Comiols i també per aprofitar el tall d'una petita explotació d'àrids per veure les relacions i diferències entre la roca (conglomerat), el mantell d'alteració o regolita (clastes angulosos de gelifracció) i el sòl (sòl bru calcari).

Si al coll de Comiols us ha quedat algun dubte sobre la geologia del territori, el Museu de la Conca Dellà (parada 3) és el lloc escaient per a acabar-ho d'aclarir. A la planta baixa hi ha una maqueta i una columna estratigràfica del territori que permeten entendre el mapa geològic com a resultat de la intersecció entre el nivell topogràfic i la constitució geològica.

Esllavissades i despreniments són dos mecanismes d'evolució dels vessants que se'ns mostren arreu per tota la Conca (parades 4-Conques, 5-
Basturs, 6-Carretera de Sant Salvador, i 8-Puigcercós, a la fig. 3, entre d'altres). L'erosió hídrica, molt intensa, produïda sobre les margues, és la responsable dels despreniments de roca dura per soscavació.

Aquesta mateixa erosió, duta a l'extrem, forma zones intensament aixaragallades (badlands) que són les principals àrees font dels sediments responsables de la colmatació de l'embassament de Terradets (parada 10), on s'hi formen magnífics deltes (figura 4).

Revisareu també la utilitat, avantatges i inconvenients de les actuacions humanes sobre els cursos d'aigua en els dics de Vilamitjana (parada 7) i la presa de Terradets (parada 11).

Analitzareu també l'aigua com a recurs energètic i com a recurs material. L'estudi de l'aquífer confinat de la Conca Dellà es complementa amb un problema que permet prendre consciència de la importància quantitativa de les aigües subterrànies respecte a les superficials.

Les roques dures d'aquesta zona són, principalment, calcàries, que en climes que permeten la circulació d'aigua líquida s'acaben dissolent i formant relleus exocàrstics (dolines i congostos) i endocàrstics (coves, fig. 5). Sota aquestes condicions, la circulació d'aigua és principalment subterrània, sortint a l'exterior de manera natural concentrada (fonts, dolines, fig. 2), natural difusa (directament per rius) o artificial (pous). Moltes parades permeten veure relleus càrstics i manifestacions de la circulació subterrània de l'aigua.

Finalment, cal comentar que tot el recorregut és bastant accidentat i una bona part de la carretera és molt nova, de manera que es poden observar totes les modalitats d'actuacions d'estabilització de talussos: xarxes antidespreniment (pujant cap a Comiols), murs de pedra seca (de Benavent a Isona), replantació amb espècies autòctones (boix), ancoratges (tram nou de la carretera de Terradets), àmplies cunetes...etc.

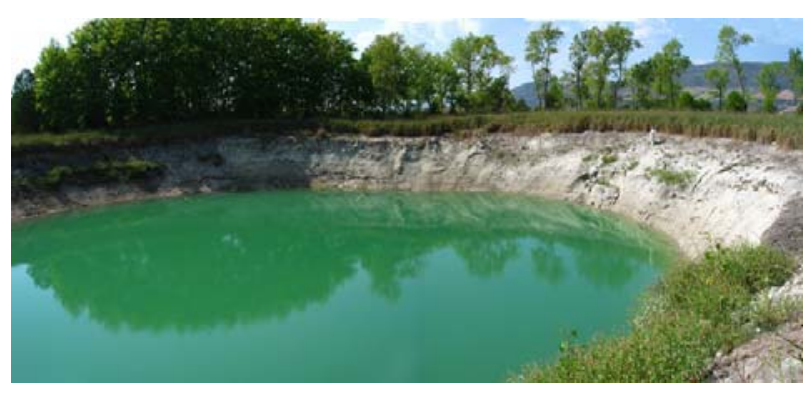

Figura 2. Dolina gran de Basturs mostrant el nivell piezomètric de l'aqüífer, uns 8 metres per sota del nivell màxim. 


\section{Ús del material}

El material està dissenyat per tal que qualsevol docent pugui realitzar l'itinerari de forma autònoma amb els seus alumnes, després d'haver-lo seguit de forma individual. Es presenta una gran quantitat d'informació, acompanyada de moltes imatges preses des del punt precís on es fa cada parada, per tal de facilitar la identificació dels llocs i l'explicació dels conceptes i processos medioambientals que facin al cas.

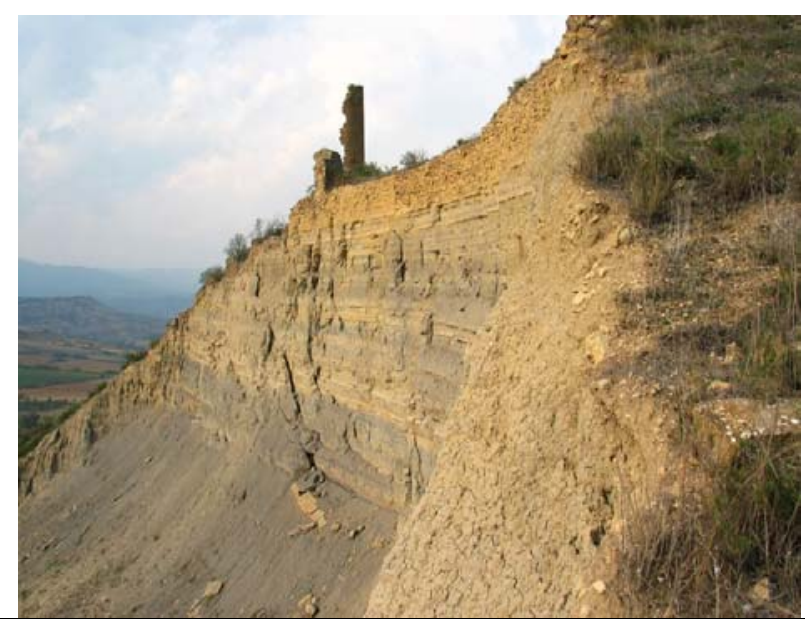

Figura 3. L'esllavissada de Puigcercós va migpartir el poble vell.

Conscient de la diversitat d'enfocaments i d'ordenacions dels continguts que diferents professors fan, he intentat facilitar al màxim la reelaboració del material, permetent, des de la pàgina web, baixar tota la informació textual i gràfica en format doc (Word), aplicació que facilita als usuaris el retallat, copiat i enganxat dels continguts.

Personalment aconsellaria als usuaris la descàrrega, impressió i grapat o enquadernat de tots els fitxers doc de l'itinerari. Els números de pàgina en faciliten el muntatge. A continuació caldria que fessin la sortida sense alumnes, per tal d'identificar els llocs i associar les explicacions del text amb les observacions sobre el territori. Aquest procediment hauria de capacitar qualsevol docent per fer la sortida amb alumnes.

Les qüestions i problemes relacionats amb cada parada es poden anar plantejant durant la sortida, tot i que l'execució per part dels alumnes caldrà ferla més tard, a l'aula, com a aplicació d'allò que s'ha vist i com a record.

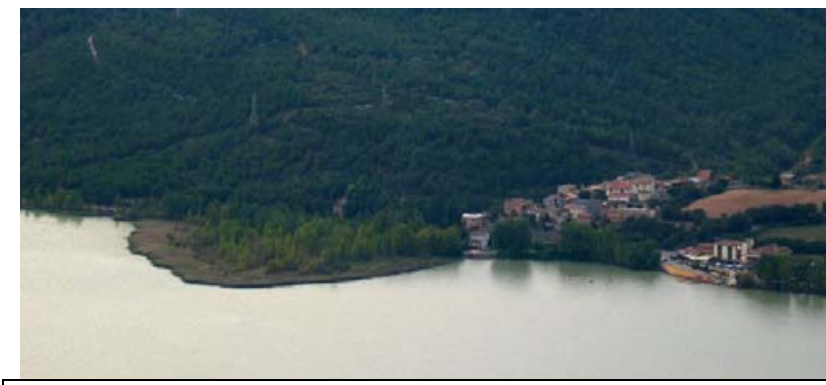

Figura 4. El delta de Cellers, a la imatge, juntament amb el del Barcedana i el de la Noguera Pallaresa, constitueixen les principals manifestacions de l'aport de sediments a l'embassament.

Alguns problemes, per la seva complexitat, és preferible afrontar-los durant una classe, amb el guiatge del professor.

\section{Nivell}

Ajustat a les Ciències de la Terra $i$ del Medi Ambient del Batxillerat Científic, en el programa de les quals es basa la selecció de continguts de la sortida.

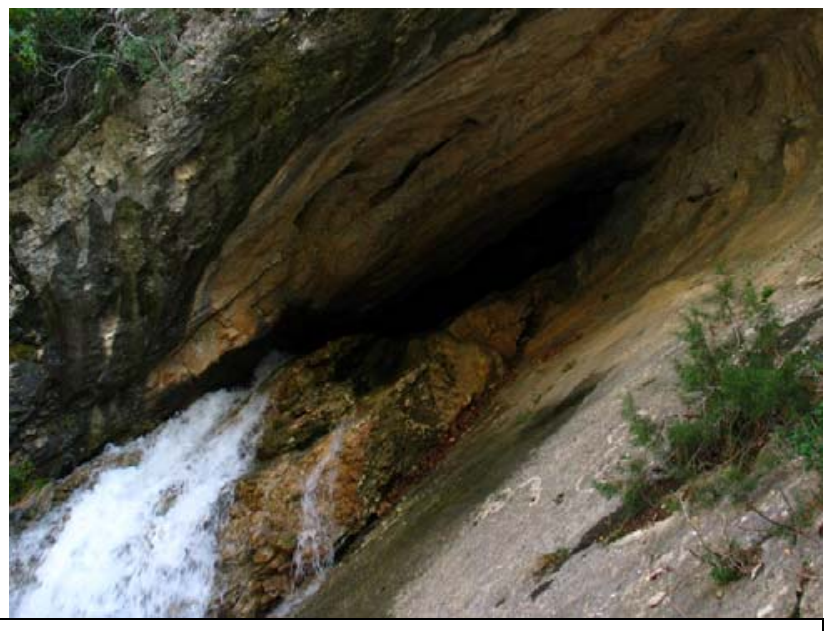

Figura 5. Brollador del Forat de l'Or.

Molt fàcilment adaptable, per simplificació, a sortides de $3 r$ o 4 t d'ESO.

També es poden seleccionar materials per als Cicles Formatius amb continguts en Ciències Ambientals com ara Tècnic en Treballs Forestals $i$ de Conservació del Medi Natural (grau mitjà) o el de Tècnic Superior en Gestió i Organització de Recursos Naturals i Paisatgístics. 
ANNEX 1

Denominació i objecte d'interès central de cada parada

\begin{tabular}{|l|l|l|}
\hline $\begin{array}{l}\text { Núm. } \\
\text { parada }\end{array}$ & Lloc & Objecte d'interès més important \\
\hline 1 & Coll de Comiols & Geologia i hidrogeologia de la zona \\
\hline 2 & Benavent de la Conca & Despreniments; roca, regolita i sòl \\
\hline 3 & Museu de la Conca Dellà & Maqueta i columna estratigràfica \\
\hline 4 & Conques & Pou artesià \\
\hline 5 & Estanys de Basturs & Dolines i nivell piezomètric; esfondraments \\
\hline 6 & Carretera de Sant Salvador & Badlands, erosió i despreniments \\
\hline 7 & Vilamitjana (ITV Tremp) & Dics fluvials \\
\hline 8 & Puigcercós & Esllavissada rotacional \\
\hline 9 & Pont del Barcedana & Cabals màxims previsibles \\
\hline 10 & Mirador de Llimiana & Colmatació d'embassaments i deltes \\
\hline 11 & Presa de Terradets & Presa i central hidroelèctrica \\
\hline 12 & Congost de Terradets & Congost, surgències i coves \\
\hline
\end{tabular}




\section{ANNEX 2}

Mapa esquemàtic de la Conca de Tremp

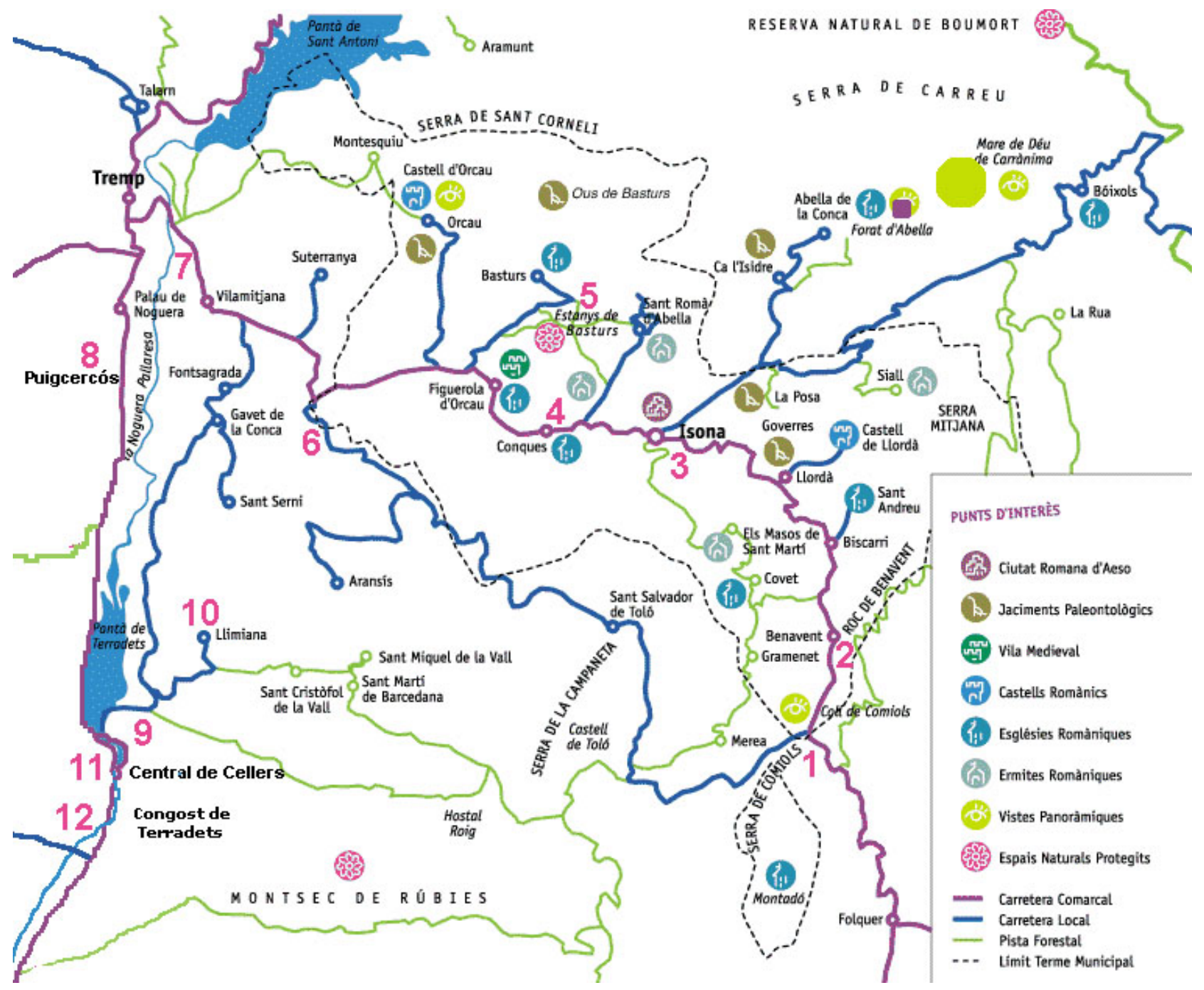

(modificat de www.xtec.es/entitats/spcn/Tremp/tremp1.htm) 